\title{
Proceeding Paper \\ Comparative Evaluation of Anti-Corrosion Coatings for NdFeB-Type Magnets with Respect to Performance and Recyclability via Hydrogen-Assisted Recycling (HPMS) ${ }^{\dagger}$
}

\author{
Carlo Burkhardt ${ }^{1, *(\mathbb{D})}$, Antje Lehmann ${ }^{1}$, Peter Fleissner ${ }^{1}$, Laura Grau ${ }^{1}$, Mirko Trautz ${ }^{1}$, Maximilian Mungenast ${ }^{1}$, \\ Benjamin Podmiljšak ${ }^{2}$ and Spomenka Kobe ${ }^{2}$ \\ 1 Institute for Precious and Technology Metals, Pforzheim University, Tiefenbronner Straße 65, \\ 75175 Pforzheim, Germany; antje.lehmann@hs-pforzheim.de (A.L.); peter.fleissner@hs-pforzheim.de (P.F.); \\ laura.grau@hs-pforzheim.de (L.G.); mirko.trautz@hs-pforzheim.de (M.T.); \\ maximilian.mungenast@hs-pforzheim.de (M.M.) \\ 2 Jožef Stefan Institute, Jamova cesta, 1000 Ljubljana, Slovenia; benjamin.podmiljsak@ijs.si (B.P.); \\ spomenka.kobe@jsi.si (S.K.) \\ * Correspondence: carlo.burkhardt@hs-pforzheim.de; Tel.: +49-7231-28-6063 \\ + Presented at International Conference on Raw Materials and Circular Economy, Athens, Greece, \\ 5-9 September 2021.
}

check for

updates

Citation: Burkhardt, C.; Lehmann, A.; Fleissner, P.; Grau, L.; Trautz, M.; Mungenast, M.; Podmiljšak, B.; Kobe, S. Comparative Evaluation of Anti-Corrosion Coatings for NdFeB-Type Magnets with Respect to Performance and Recyclability via Hydrogen-Assisted Recycling (HPMS). Mater. Proc. 2021, 5, 87. https://doi.org/10.3390/materproc 2021005087

Academic Editor: Anthimos Xenidis Published: 28 December 2021

Publisher's Note: MDPI stays neutral with regard to jurisdictional claims in published maps and institutional affiliations.

Copyright: (c) 2021 by the authors Licensee MDPI, Basel, Switzerland. This article is an open access article distributed under the terms and conditions of the Creative Commons Attribution (CC BY) license (https:// creativecommons.org/licenses/by/ $4.0 /)$.

\begin{abstract}
Various anti-corrosion coatings used on commercially available NdFeB-type magnets were comparatively examined for their durability and suitability for magnet reprocessing by hydrogenassisted recycling (HPMS). Layer thickness and structure were determined by systematic microstructural analysis, and a standardized corrosion test was used to assess the durability of each layer. Chemical composition of the coatings was analyzed using SEM/EDS and ICP-OES. HPMS behavior was investigated using in situ video monitoring. The results of the presented investigations are an important contribution for the implementation of a sorting and labeling system to support and facilitate a commercially viable recycling of permanent magnets on an industrial scale.
\end{abstract}

Keywords: $\mathrm{NdFeB}$; permanent magnet; circular economy; recycling; hydrogen; corrosion; coating

\section{Introduction}

It is impossible to imagine the future without permanent magnets based on rare earth elements (REEs). They are essential for converting electricity into mechanical energy, especially for electric motors and electric generators. Therefore, they are key materials for the fulfilment of the "European Green Deal" towards a carbon neutral society [1]. The fact that Europe has limited access to exploitable REEs makes them the most important raw materials for integration into the circular economy.

Hydrogen-assisted recycling (HPMS) is a promising reprocessing route for end-of-life (EOL) magnets [2] with $88 \%$ less energy consumption and $98 \%$ less human toxicity compared to primary production of sintered magnets [3]. In HPMS, the EOL magnet is exposed to hydrogen in a closed vessel at slightly elevated pressure for a short time, which hydrogenates and thus expands the Nd-rich grain boundary phase, causing the bulk material to disintegrate into friable, hydrogenated, and demagnetized $\mathrm{NdFeB}$ granules/powder that can be mechanically separated from the remaining impurities [4]. HPMS is a relatively simple and reproducible process for producing sintered or polymer bonded magnets from single source EOL magnets [5].

To enable a commercially viable circular economy for NdFeB magnets using HPMS for different scrap sources, it is vital to investigate the influence of different anti-corrosion coatings currently on the market, since (1) different penetration properties for hydrogen may have a significant influence on the kinetics of the hydration reaction and regarding (2) the quality of the resulting recycled material [6]. Thus, (3) the magnetic performance of 
the recycled magnets may be strongly influenced by potential powder impurities due to coating residues.

The findings of this study are an important input for a recycling, sorting, and labelling system for permanent magnets developed under the EU-funded MaXycle and SUSMAGPRO projects, which is planned to be introduced to facilitate commercially attractive EOL magnet recycling [6].

\section{Materials and Methods}

A series of NdFeB magnets equipped with 13 commercially available and widely used anti-corrosion coatings were compared to evaluate and rank performance and recyclability with HPMS. The coatings ranged from passivation and electroplated metal coatings to spray-coated polymers and multilayers. The coating types are listed in Table A1. The magnet batches had comparable magnet grades $(\mathrm{N} 38 \mathrm{SH})$ but, due to availability, different geometries. The initial corrosion protection of the coatings was evaluated by a standardized corrosion test. Coating thicknesses, coating structure, and chemical composition of the as-received magnet coatings were analyzed by optical and scanning electron microscopy (SEM), energy dispersive X-ray spectrometry (EDS), and inductively coupled plasma optical emission spectrometry (ICP-OES). The HPMS behavior (initiation time at a given pressure and resulting particle size distribution) both in the as-received state and, if necessary, in the mechanically fractured state, was investigated, using a tailor-made laboratory-scale HPMS reactor for in situ studies and real-time video recording through a gauge glass. Contamination of the resulting powders by coating residues was analyzed in detail, as was the possibility of separating the coatings from the powders by sieving after HPMS treatment. In an attempt to exclude superimposed influences, three individual samples of each magnet batch were subjected to the following treatments (see also overview in Figure A1):

Sample 1: By means of SEM/EDS, a microstructural analysis of a cross-section of each magnet type was performed, including a determination of the number and respective thickness of the coating layers. Particular attention was paid to the transition area between the base material and the coating.

Sample 2: A salt spray test according to ISO 9227 and EN 60068-2-52 was performed with each magnet type at a chamber temperature of $40{ }^{\circ} \mathrm{C}$ for $240 \mathrm{~h}$ with a salt water temperature of $35^{\circ} \mathrm{C}$ and a concentration of $5 \% \mathrm{NaCl}$ (HAST test). All samples were visually inspected at $24 \mathrm{~h}$ intervals.

Sample 3: This sample was treated with HPMS with 3 bar hydrogen pressure at room temperature in a custom-made gauge glass reactor, and the hydrogen decrepitation process was video-monitored in situ with a single frame camera at 0.1 frames per second (fps). When no decrepitation reaction started after $2.75 \mathrm{~h}$ due to $\mathrm{H}_{2}$-impermeable coatings, the magnet was manually broken into 2-3 pieces, allowing hydrogen uptake of the bulk material. Subsequently, HPMS was repeated with identical process parameters. The resulting hydrogenated powders were vibration sieved in a cascade (mesh sizes of $1000 \mu \mathrm{m}$, $500 \mu \mathrm{m}, 250 \mu \mathrm{m}, 125 \mu \mathrm{m}, 63 \mu \mathrm{m}, 45 \mu \mathrm{m}$, and $25 \mu \mathrm{m}$, respectively) for $10 \mathrm{~min}$. The yield per mesh size was determined by weighing the individual fractions on a high-precision scale. ICP-OES was used to quantify the coating residues per sieve fraction in weight percent. Combustion analysis was used to measure the carbon content of each powder fraction to relate the $\mathrm{C}$ content to possible coating residues.

\section{Results}

\subsection{Microstructural Analysis}

All magnets show a typical NdFeB microstructure (Figure A2) consisting of hardmagnetic $\mathrm{Nd}_{2} \mathrm{Fe}_{14} \mathrm{~B}$ grains separated by the Nd-rich grain boundary phase. With SEM, the coating structures and thicknesses could be visualized and quantified, see Figure A2 and results in Table A2. 


\subsection{HAST Test}

To evaluate the initial performance of the coatings as corrosion protection, a salt spray test was performed according to ISO 9227 and EN 60068-2-52. The best performance was observed for the $\mathrm{Ni}$ - and $\mathrm{Cu}$-containing coatings, while severe corrosion attack was observed after only $24 \mathrm{~h}$ for the passivated and "color $\mathrm{Zn}$ " coated magnet. The results are summarized in Figure A3.

\subsection{HPMS}

All magnets examined could be reduced to a hydrogenated powder by HPMS, but with different initiation and processing times, depending on the type/structure of the coating. With the exception of the passivated magnets $\mathrm{S} 1, \mathrm{~S} 3$, and S4, all samples had to be broken into two to three pieces to initiate the reaction. The morphology of the resulting powder and coating flakes also varied with coating type (Figures 1 and A4).
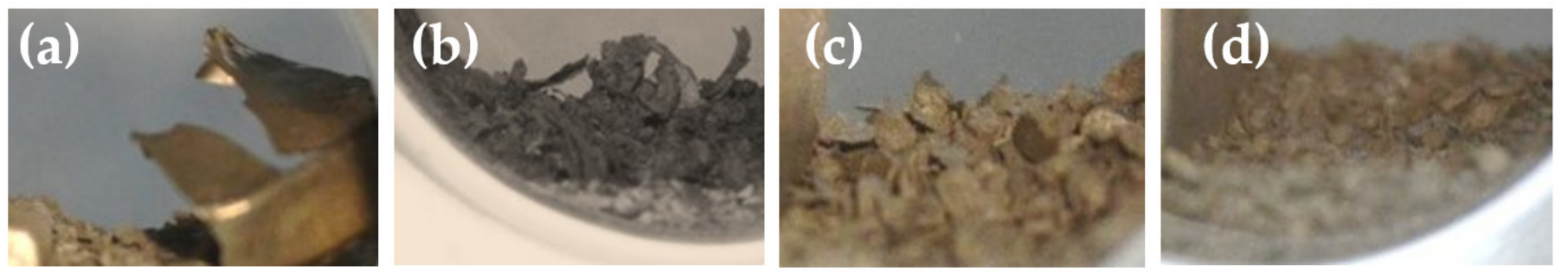

Figure 1. Specification of the hydrogenated magnetic material. (a) Non-decomposed coating: large coating areas remain unbroken, but are deformed by the volume expansion of the hydrogenated magnetic material, resulting in coating carcasses. (b) Single flakes: formed when the coating is not disintegrated by $\mathrm{H}_{2}$ but is peeled off in flakes. (c) Mixed flakes: caused by better adhesion of the coating to the magnetic material and not by cohesion of the coating itself. (d) Disintegrated coating: small flakes caused by low cohesion or by reaction with $\mathrm{H}_{2}$.

\subsection{Quantification and Evaluation of Coating Residues \\ 3.4.1. ICP-OES}

After vibration sieving, the chemical composition of each powder fraction from Section 3.3 was analyzed by ICP-OES (Table A2). To determine the respective degree of contamination of the magnetic powder by coating residues, the weight percentage of metallic coating elements per fraction was compared with the total weight of the fraction after sieving. To simplify the evaluation, weight clusters were formed to quickly give an indication of the amount of coating residue in a given fraction. Until the completion of the remanufacturing tests and thus the availability of magnetic characteristic values, $0.5 \mathrm{wt} \%$ was assumed as a provisional limit value for the metallic residues. The best yields were obtained for magnet type S6 (non-decomposed coating), allowing $>95 \%$ of the non-contaminated magnet material to be recycled, while for magnet type S9 (disintegrated coating) only $22 \%$ of the non-contaminated magnet material could be produced (see Figure A5). With the exception of S6 and S8, no dependency was found between the coating morphology after HPMS and the contamination levels in the respective sieve fractions.

\subsubsection{Analyses}

The carbon content of the samples with carbon-based (polymeric) coatings was measured and evaluated in a similar way as in Section 3.4.1 (Figure A6). Assuming a max. allowable value of $0.1 \% \mathrm{C}$ for good magnetic properties [7], S11 (non-decomposed coating) shows the highest yield of viable material (70\%), while sample S13 (single flakes) could not deliver any useable HPMS material at all. In contrast to the results in Section 3.4.1, good agreement was found between the coating morphology of the samples and their respective $\mathrm{C}$ contents after sieving. 


\section{Discussion}

In this investigation, a range of $\mathrm{NdFeB}$ magnets, equipped with 13 commercially available and widely used anti-corrosion coatings, was compared to evaluate and classify performance and recyclability via the environmentally favorable HPMS process. The coatings ranged from passivation over electroplated metal coatings to spray-coated polymers and multilayers.

The initial corrosion protection performance of the coatings differs significantly, with electroplated multilayer coatings (S5-S8) exhibiting a much better performance than single layer (S9-S10), passivated (S1-S4), or spray-coated (S13) coating types. With respect to corrosion protection, electroplated coatings containing $\mathrm{Ni}$ (and $\mathrm{Cu}$ ) show a superior behaviour to $\mathrm{Zn}$-containing coatings. Single layer epoxy (S12) shows good corrosion protection, and additional epoxy coatings can improve the performance of electroplated corrosion protection coatings (S11). Similar or better performance, however, can also be achieved with an additional outer Ni layer (S8).

All investigated magnets could be disintegrated into a hydrogenated powder by HPMS, however, with varying initiation and processing times, depending on the type/structure of coating. With the exception of the passivated magnets, it seems to be necessary to break the coated magnets into pieces or at least to damage the coating to let hydrogen enter the magnetic material and thus ensure decrepitation.

One very important factor in terms of processing costs and the quality of the reprocessed magnet is the avoidance of coating contamination. It was found that during hydrogen-assisted recycling using HPMS, some coating types break down into indistinguishable small flakes, while others remain as larger flakes or carcasses. Unexpectedly, no dependency was found between the coating morphology and the degree of contamination of the sieved HPMS powder with respect to metallic coating residues. It is assumed that the applied vibration sieving favors further fragmentation of the coating particles, even if it is performed without aids such as steel balls, as in the present study.

Under the conditions employed, the best separation was found for magnet type S6, which allowed the recycling of $>95 \%$ of non-contaminated magnet material, while only $22 \%$ of non-contaminated magnet material could be obtained with magnet type S9. It is important to note that a certain degree of contamination, as caused by metallic coating residues (e.g., $\mathrm{Cu}, \mathrm{Ni}, \mathrm{Zn}$, etc.), is acceptable for the recycling of high-performance permanent magnets. For reference, see also Figure A5.

In further work, the individual threshold values for different elements will be determined with comparative measurements of the magnetic properties of reprocessed magnets from the respective HPMS powder fractions.

For the investigated samples with carbon-based (polymeric) coatings, on the other hand, good agreement was found between the coating morphology of the samples and their respective $C$ content after sieving. Assuming a maximum carbon content of $0.1 \%$ to achieve competitive magnetic properties, the polymeric coating of sample S11 allowed a yield of 70\% non-contaminated magnetic material, while in sample S13 finely distributed carbon contaminations were found in all sieve fractions, making the material unsuitable for recycling via HMPS under the currently applied (sieving) conditions.

\section{Conclusions}

Chemical composition and physical structure of anti-corrosion coatings play an important role in HPMS recycling and subsequent reprocessing of high-performance $\mathrm{NdFeB}$ magnets; coating particles are a potential source of contamination in HPMS powders and, depending on their nature, mechanical separation of the coating residues from the magnet material can be very difficult and thus expensive.

To ensure cost-effective and high-quality HPMS recycling of NdFeB-type magnets, it is necessary to separate the magnets of different layer types for customized further processing. To achieve high recycling rates, a machine-readable classification and labeling system, such as the one developed in the ERA-MIN2 project MaXycle, seems vital. 
From a design-for-recycling perspective, $\mathrm{Ni}-\mathrm{Cu}$ type electroplated multilayer corrosion protection coatings are favorable for HPMS recycling, while some coatings (e.g., Everlube 6155) are not recommended. Further work is required to determine the maximum tolerable levels of contamination with metallic coating residues such as $\mathrm{Zn}, \mathrm{Ni}$, and $\mathrm{Cu}$ and to optimize the mechanical separation of magnetic material and coating residues, e.g., by wind sifting.

In this study, the HPMS procedure was performed without prior thermal demagnetization of the EOL magnets. Future work will also include the evaluation of a possible different recycling behavior of the investigated corrosion protection coatings after a prior heat treatment of $350{ }^{\circ} \mathrm{C}$.

Acknowledgments: SUSMAGPRO has received funding from the European Union's Horizon 2020 research and innovation programme under grant agreement No. 821114, MaXycle has received funding from the ERA-MIN2 research and innovation programme on raw materials to foster circular economy. The authors would like to thank Badrinath Veluri of Grundfos S.A. (Denmark) for the provision of the magnets and Volker Jahns of ZF AG (Germany) for the assistance with the corrosion tests.

\section{Appendix A}

Table A1. Geometry and coating data of the investigated samples.

\begin{tabular}{|c|c|c|c|}
\hline Sample Number & Surface Treatment & Type & Size \\
\hline S1 & \multirow{4}{*}{ Passivation } & "Normal" & $27.5 \times 12 \times 3$ \\
\hline $\mathrm{S} 2$ & & Phosphate & $27.5 \times 12 \times 3$ \\
\hline S3 & & "NT1" & $27.5 \times 12 \times 3$ \\
\hline S4 & & "M-coating" & $27.5 \times 12 \times 3$ \\
\hline S5 & \multirow{2}{*}{ Electroplating } & $\mathrm{Ni}-\mathrm{Ni}$ & $21.6 \times 15 \times 2.5$ \\
\hline S6 & & $\mathrm{Ni}-\mathrm{Cu}-\mathrm{Ni}$ & D25-d4.15 × 7 \\
\hline S7 & Electroplating & $\mathrm{Ni}-\mathrm{Cu}-\mathrm{Sn}$ & $21.6 \times 15 \times 2.5$ \\
\hline S8 & Electroplating/chemical & $\mathrm{Ni}-\mathrm{Cu}-\mathrm{Ni} /$ chem $\mathrm{Ni}$ & $34 \times 16 \times 2.7$ \\
\hline S9 & \multirow{2}{*}{ Electroplating } & “Blue" Zn & $\mathrm{D} 24.5 \times 3.4$ \\
\hline S10 & & “Color" Zn & D37.2-d4.15 × 5 \\
\hline S11 & Electroplating/coating & $\mathrm{Ni}-\mathrm{Cu} / \mathrm{Epoxy}$ & $21.6 \times 15 \times 2.5$ \\
\hline S12 & Coating & Single Epoxy & $30 \times 14 \times 4$ \\
\hline S13 & Coating & "Everlube 6155" & $21.6 \times 15 \times 2.5$ \\
\hline
\end{tabular}

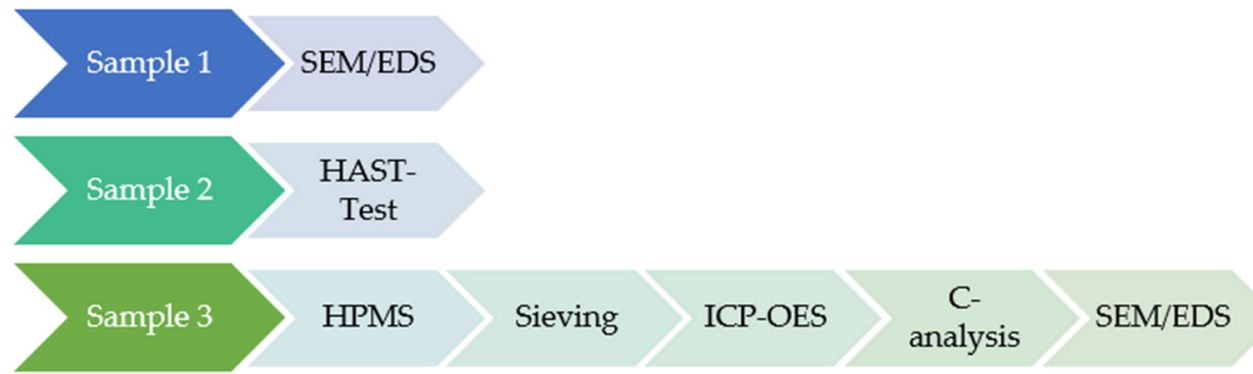

Figure A1. Overview of the sample splitting and the used analysis methods. 

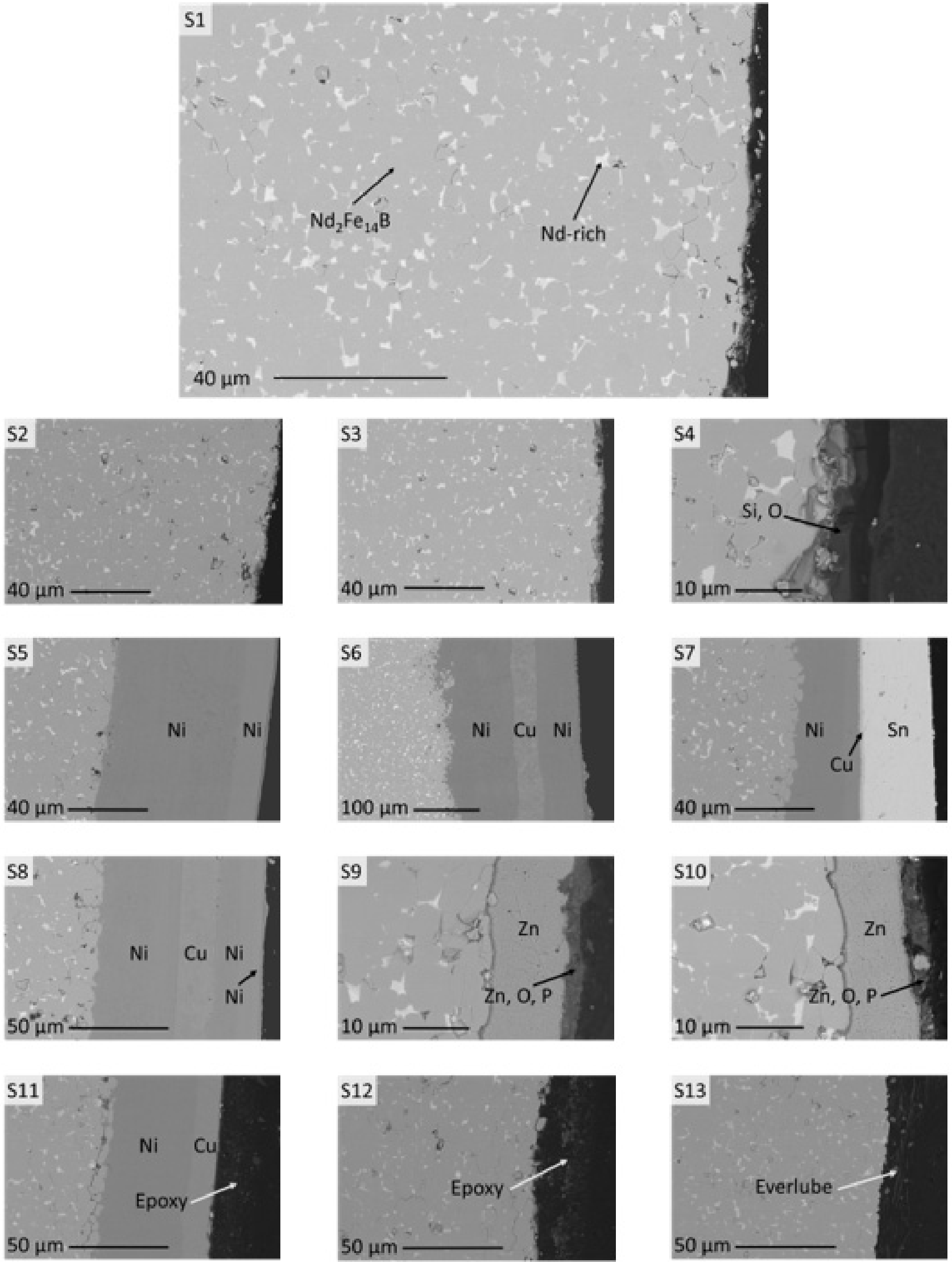

Figure A2. SEM images of the investigated NdFeB magnet samples S1-S13 showing microstructure and coatings. 
Table A2. Coating thickness and elemental distribution, analysed with SEM (see also Figure A2) and measured elemental coating residues analyzed by ICP-OES and C/S (see also Figures A5 and A6).

\begin{tabular}{|c|c|c|c|c|c|}
\hline $\begin{array}{l}\text { Sample } \\
\text { Number }\end{array}$ & Number of Layers & $\begin{array}{l}\text { Layer Thickness } \\
{[\mu \mathrm{m}]}\end{array}$ & $\begin{array}{c}\text { Coating } \\
\text { Thickness Total } \\
{[\mu \mathrm{m}]}\end{array}$ & $\begin{array}{l}\text { Chemical } \\
\text { Composition } \\
\text { (EDS) }\end{array}$ & $\begin{array}{c}\text { Coating Residues } \\
\text { (ICP-OES and } \\
\text { C/S) }\end{array}$ \\
\hline S1 & 0 & 0 & 0 & like bulk & none \\
\hline S2 & 0 & 0 & 0 & like bulk & none \\
\hline S3 & 0 & 0 & 0 & like bulk $+\mathrm{C}, \mathrm{O}$ & none \\
\hline S4 & 1 & 5 & 5 & $\mathrm{Si}, \mathrm{O}$ & none \\
\hline S5 & 2 & $66 ; 16$ & 82 & $\mathrm{Ni} ; \mathrm{Ni}$ & $\mathrm{Ni}$ \\
\hline S6 & 3 & $89 ; 37 ; 64$ & 190 & $\mathrm{Ni} ; \mathrm{Cu} ; \mathrm{Ni}$ & $\mathrm{Ni}, \mathrm{Cu}$ \\
\hline S7 & 3 & $33 ; 2 ; 35$ & 70 & $\mathrm{Ni} ; \mathrm{Cu} ; \mathrm{Sn}$ & $\mathrm{Ni}, \mathrm{Cu}, \mathrm{Sn}$ \\
\hline S8 & 4 & $40 ; 19 ; 19 ; 6$ & 84 & $\mathrm{Ni} ; \mathrm{Cu} ; \mathrm{Ni} ; \mathrm{Ni}, \mathrm{P}$ & $\mathrm{Ni}, \mathrm{Cu}$ \\
\hline S9 & 1 & 16 & 16 & $\mathrm{Zn}$ & $\mathrm{Zn}$ \\
\hline S10 & 1 & 13 & 13 & $\mathrm{Zn}$ & $\mathrm{Zn}$ \\
\hline S11 & 3 & $41 ; 14 ; 20$ & 75 & $\mathrm{Ni} ; \mathrm{Cu} ; \mathrm{C}$ & $\mathrm{Ni}, \mathrm{Cu}, \mathrm{C}$ \\
\hline $\mathrm{S} 12$ & 1 & 19 & 19 & $\mathrm{C} ; \mathrm{Al} ; \mathrm{Si} ; \mathrm{Sn}$ & $\mathrm{C}$ \\
\hline S13 & 1 & 15 & 15 & $\mathrm{C} ; \mathrm{Al} ; \mathrm{P} ; \mathrm{Zn}$ & $\mathrm{Al}, \mathrm{C}$ \\
\hline
\end{tabular}

\section{S13/Everlube 6155}

S12/Single epoxy

S11/Ni-Cu-epoxy

S10/Color Zn

S9/Blue Zn

S8/Ni-Cu-Ni-Chem Ni

$\mathrm{S} 7 / \mathrm{Ni}-\mathrm{Cu}-\mathrm{Sn}$

$\mathrm{S} 6 / \mathrm{Ni}-\mathrm{Cu}-\mathrm{Ni}$

$\mathrm{S} 5 / \mathrm{Ni}+\mathrm{Ni}$

S4/M-coating

S3/NT1

S2/Phosphating

S1/Passivation

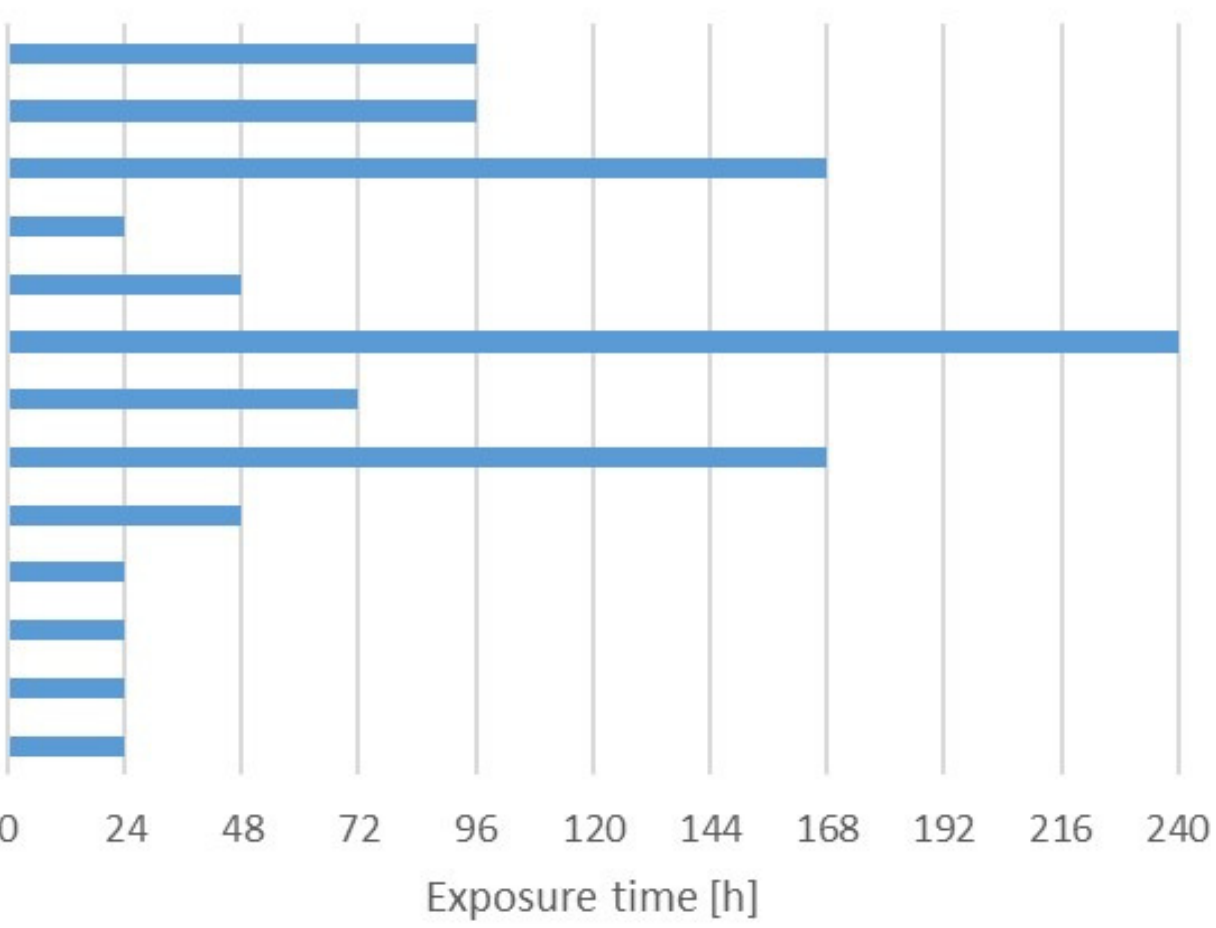

Figure A3. Start of visually observable corrosion attack. 

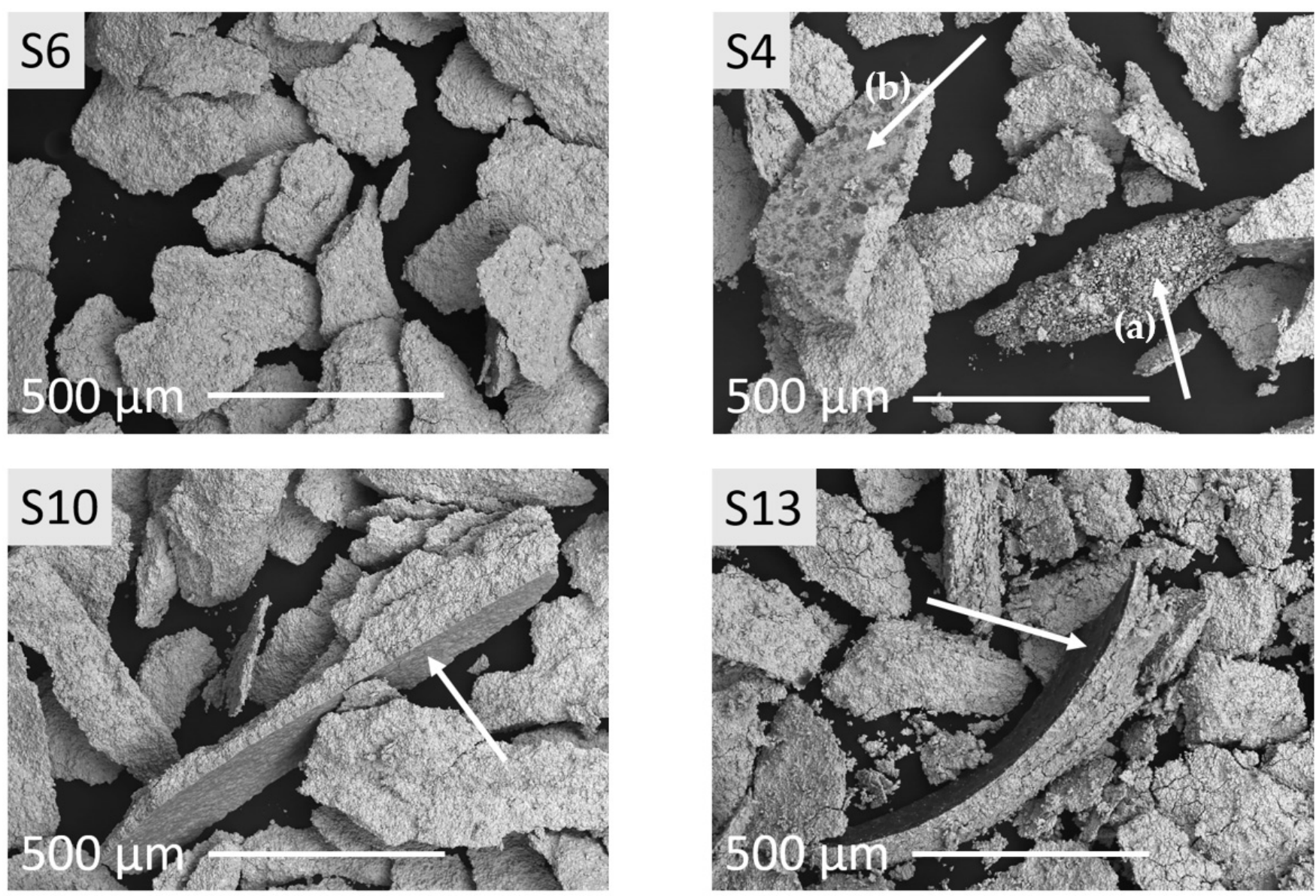

Figure A4. SEM pictures of HPMS powder samples after sieving; showing very good agreement with ICP results. (S6) No residues found. (S4) Arrows indicate fine agglomerates of Nd-Fe particles (a) and surface contaminations of $\mathrm{SiO}$ (b) resulting from the passivation. (S10) Arrow indicates large coating flake. (S13) Arrow indicates large coating flake. 


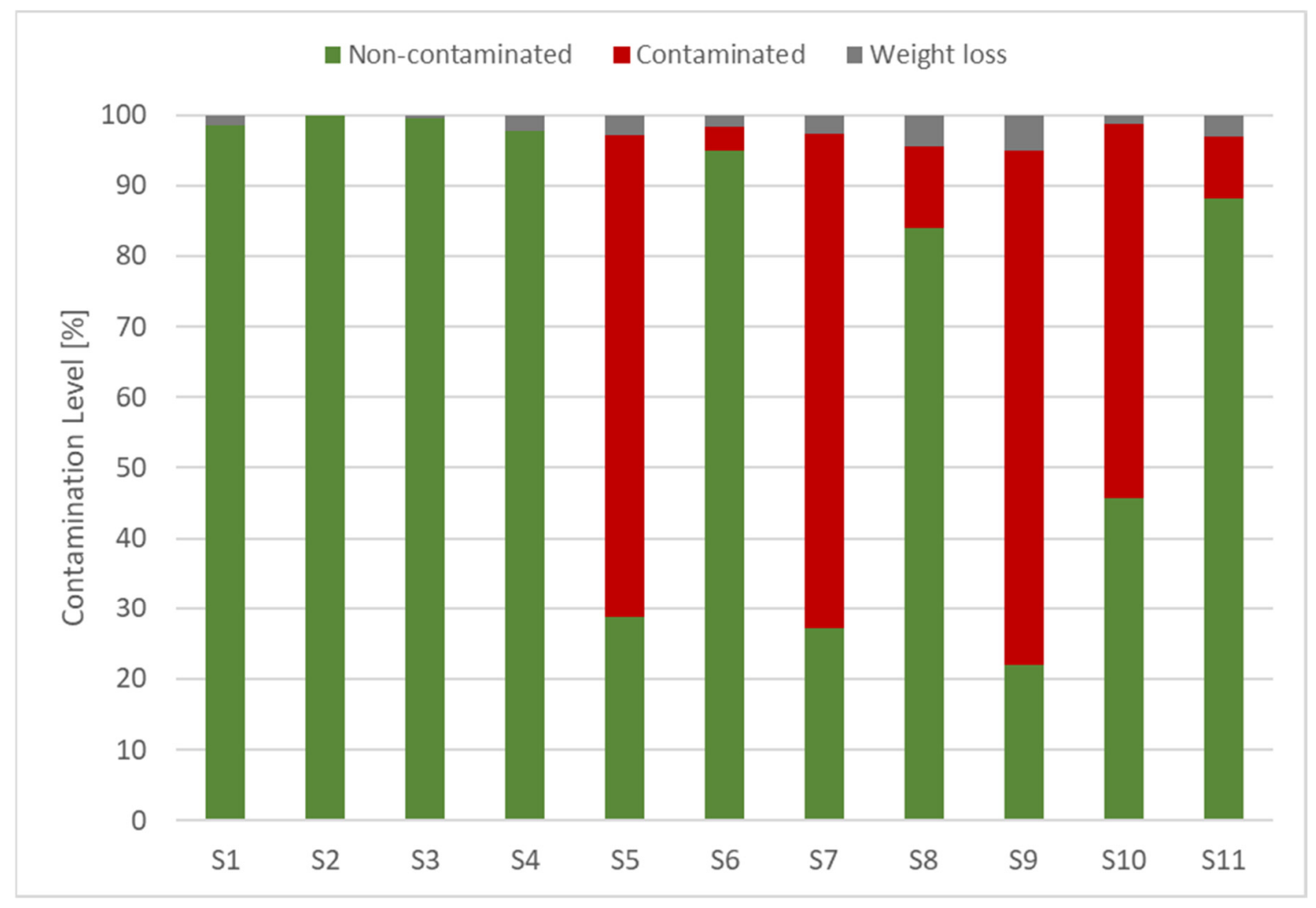

Figure A5. Contamination level of metallic residues by ICP-OES analyses (assuming a provisional limit value of $0.5 \mathrm{wt} \%$ for the metallic residues).

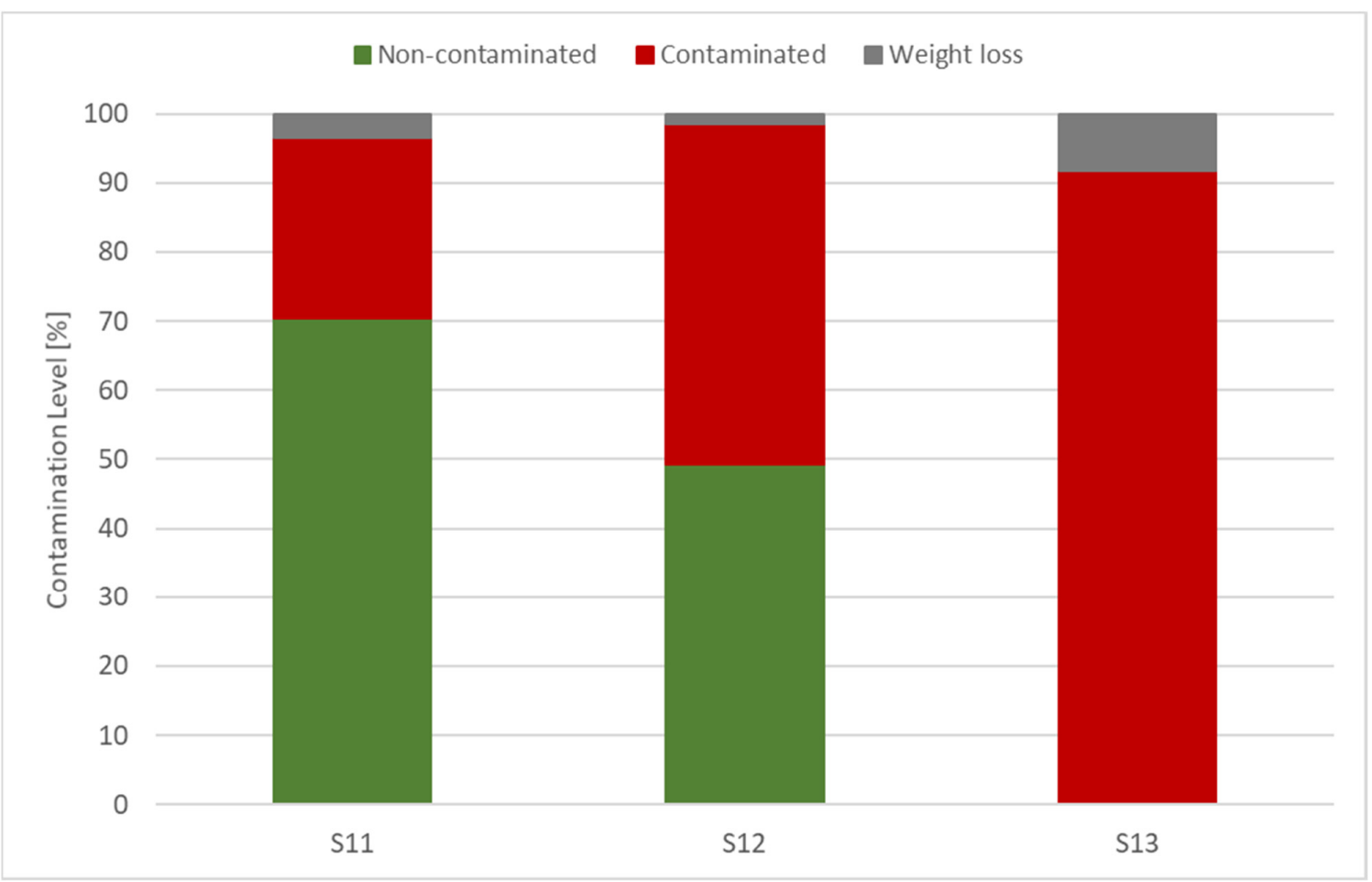

Figure A6. Contamination level of carbon residues by $\mathrm{C} / \mathrm{S}$ analyses (assuming a provisional limit value of $0.1 \mathrm{wt} \%$ for the carbon residues). 


\section{References}

1. A European Green Deal. Available online: https://ec.europa.eu/info/strategy/priorities-2019-2024/european-green-deal_en (accessed on 8 July 2021).

2. Walton, A.; Williams, A.J.; Speight, J.D.; Harris, I.R. Magnet Recycling. U.S. Patent No. US 13/169,839, 27 April 2014.

3. Sprecher, B.; Xiao, Y.; Walton, A.; Speight, J.; Harris, R.; Kleijn, R.; Visser, G.; Kramer, G.J. Life Cycle Inventory of the Production of Rare Earths and the Subsequent Production of NdFeB Rare Earth Permanent Magnets. Environ. Sci. Technol. 2014, 48, 3951-3958. [CrossRef] [PubMed]

4. $\quad$ Binnemans, K.; Jones, P.T.; Blanpain, B.; Van Gerven, T.; Yang, Y.; Walton, A.; Buchert, M. Recycling of rare earths: A critical review. J. Clean. Prod. 2013, 51, 1-22. [CrossRef]

5. Walton, A.; Yi, H.; Rowson, N.A.; Speight, J.D.; Mann, V.S.J.; Sheridan, R.S.; Bradshaw, A.; Harris, I.R.; Williams, A.J. The use of hydrogen to separate and recycle neodymium-iron-boron-type magnets from electronic waste. J. Clean. Prod. 2015, 104, $236-241$. [CrossRef]

6. Burkhardt, C.; Lehmann, A.; Podmiljsak, B.; Kobe, S. A Systematic Classification and Labelling Approach to Support a Circular Economy Ecosystem for NdFeB-Type Magnet. J. Mater. Sci. Eng. A 2020, 10, 125-133. [CrossRef]

7. Sagawa, M.; Mizoguchi, T. NdFeB System Sintered Magnet and Method for Producing the Same. U.S. Patent No. US 9028624B2, 5 December 2015. 